\title{
28 Research Square \\ The Comparation of Two Instruments for Rat Cervical 2 Hemisection Model
}

\section{LinLin Shen}

Second Hospital of Tianjin Medical University

\section{Chen Song}

Second Hospital of Tangshan

Liang Zhang

Second Hospital of Tianjin Medical University

Kai Wang ( $\nabla$ wangkaiy48@126.com )

Second Hospital of Tianjin Medical University

\section{Research Article}

Keywords: C2 hemisection, rat model, spinal cord injury, experiment methods.

Posted Date: November 1st, 2021

DOI: https://doi.org/10.21203/rs.3.rs-970957/v1

License: (9) This work is licensed under a Creative Commons Attribution 4.0 International License. Read Full License 


\section{Abstract}

The lateral C2 hemisection (HS) rat is the most studied reclinical model in the study of respiratory function after high cervical spinal cord injury. There are two main surgical methods in several studiesmicroscissors or microscalpel. This study is to evaluate the experimental results between those two methods. In this study, we performed rat lateral C2HS by microscissors (group A) or microscalpel (group B). We record cut frequency during hemisection as well as recovery of diaphragm electrophysiology by electromyogram (EMG) on the 14th day post injury. On the 14th day post injury, we record survival rate and evaluated the injury extent by hematoxylin-eosin (HE) stain. As a result, we found that group A had milder $\mathrm{C} 2$ injury extent than group B, higher survival rate on the 14th day post injury, and higher percent of peak root mean square (RMS) EMG post injury to that before injury. However, group A had larger cut frequency during hemisection. Weigh the advantages and disadvantages, microscissors seem had superiority over microscalpel.

\section{Introduction}

High cervical spinal cord injury $(\mathrm{SCl})$ results in neuromotor deficits and what most challenge neuroscientists is respiratory pathway collapse which lead to diaphragm paralysis. Fortunately, respiratory pathway had plasticity and the part recovery of EMG diaphragm occurred a few weeks after high cervical SCl. Therefore, a mushrooming number of neuroscientists try to understand the cellular mechanisms attribute to phenomenon. In this field, the emergent animal model is adult rat lateral $\mathrm{C} 2 \mathrm{HS}$ $1-10$

The hemidiaphragm is innerved by ipsilateral phrenic nuclei located in C3 6 and phrenic nuclei are innerved by bilateral rostral ventral respiratory group (rVRG) in medullary. Lateral C2HS interrupts descending bulbospinal respiratory pathways and results in temporary ipsilateral hemidiaphragm paralysis. The "crossed-phrenic phenomenon" (CPP) is defined as that the partial recovery of ipsilateral phrenic nuclei or hemidiaphragm activity in response to respiratory stressors 11,12 such as phrenicotomy 7,13 , hypercapnia and hypoxia. Crossed phrenic activity is broadly defined as any recovery of phrenic nuclei or hemidaphragm activity ipsilateral to injury, which occurs spontaneously (SCPP) or in response to respiratory stressors (CPP) ${ }^{1}$. The CPP in adult rat can be explained that the loss of ipsilateral rVRG input to the phrenic nuclei is compensated by the input from contralateral rVRG fibers crossed over the spinal cord midline below $\mathrm{C} 2$ or ipsilateral phrenic dendrites crossed over spinal cord midline to receive contralateral rVRG fibers. SCPP is a time-dependent recovery of ipsilateral phrenic nuclei or hemidiaphragm without any intervene, which need several weeks ${ }^{14-17}$ or months ${ }^{18,19}$. And it has been attributed to the formation of new synapse projecting to phrenic nuclei ${ }^{20-23}$ because the formation of new synapse requires 3 to 4 weeks ${ }^{24-27}$. In this study, we observed the SCPP during two weeks after $\mathrm{C} 2 \mathrm{HS}$. 
There are two kinds of surgery methods in $\mathrm{C} 2 \mathrm{HS}$ models. Some investigators used microscissors to perform C2 hemisection, such as Kenneth H. Minor ${ }^{28}$, Wayne W.Liou ${ }^{29}$, Gregory J Basuraused ${ }^{30}$, Yonglu Huang ${ }^{31}$, and D.D. Fuller ${ }^{32}$. Some investigators preferred microscalpel to perform C2HS, such as Tatiana Bezdudnaya ${ }^{33}$, Brendan J. Dougherty ${ }^{34}$, Warren J. Alilain ${ }^{35}$, Francis J. Golder ${ }^{36}$, Kun-Ze Lee ${ }^{37,38}$, Carlos B. Mantilla ${ }^{39}$, Ricardo Siu ${ }^{40}$, and Heather M. Gransee ${ }^{41}$. According the different structure characteristics of microscissors and microscalpel, there may be heterogeneity in some results among several studies.

In order to determinate those heterogeneity, we performed rat lateral C2HS by those two methods and recorded cut frequency during hemisection and the percent of peak RMS EMG on the 14th day post injury to that before injury. On 14thday post injury, we recorded survival rate and evaluated the $\mathrm{C} 2$ injury extent by HE stain.

\section{Material And Methods 2.1 Animals}

Twenty 12 weeks old female Sprague Dawley rats with initial body weight 280 320g were used and were randomly assigned to group $A$ and group $B$ in this study. Anesthesia was performed with isoflurane inhalation $\left(\mathrm{O}_{2}\right.$ velocity of flow $500-700 \mathrm{ml} / \mathrm{min}$, induced concentration $3-4 \%$, maintain concentration 2$2.5 \%)$.

All experimental protocols were approved the ethics committee of Tianjin Medical University. All methods were carried out in accordance with relevant guidelines and regulations. All methods are reported in accordance with ARRIVE guidelines

\subsection{Electrophysiology}

The electrodes were implanted three days before $\mathrm{C} 2 \mathrm{HS}$ to avoid the effect of laparotomy to respiratory. In order to verify completeness of $\mathrm{C} 2 \mathrm{HS}$, silence of ipsilateral hemidiaphragm EMG activity was confirmed at anesthesia condition at the time of surgery and on the third days post $\mathrm{C} 2 \mathrm{HS}$. Briefly, rats were placed on a heating pad to maintain a constant body temperature $\left(37^{\circ} \mathrm{C}\right)$ and laparotomy was performed to expose the diaphragm and custom-made bipolar electrodes (AS631; Cooner Wire, Chatsworth, CA) were implanted into the both slides mid-costal hemidiaphragm in such a manner that an uninsulated $3 \mathrm{~mm}$ segment was embedded within the diaphragm, as previously described ${ }^{41-45}$. The electrode wires gone subcutaneously and gone out in the dorsum of the animal and were used for chronic EMG recordings for up to two weeks. Signals were amplified (2000x) and band pass-filtered $(20 \mathrm{~Hz}-1 \mathrm{kHz})$ by amplifiers (IPS 100C-1, BIOPAC Systems) and raw EMG signals were recorded by a Powerlab data acquisition device connected to a computer and analyzed using LabChart 8 Pro software (AD Instruments, Dunedin, New Zealand). The root mean square (RMS) of EMG was integrated (50 ms decay). Motor unit recruitment is reflected by peak RMS EMG. The higer peak value, the more motor unit recruited. 


\subsection{Lateral C2HS}

For each animal, C2 spinal cord exposure was performed following the method of Emilie Keomani ${ }^{46}$. Briefly, perform a posterior cervical midline incision with scissors caudally $30 \mathrm{~mm}$ from ear level. Cut the acromiotrapezius muscle rostro-caudally and dissociate the rhomboid muscle to access the spinalis muscles. Then, the $\mathrm{C} 2$ vertebral plate with a prominent apophysis was exposed after retracting the spinalis muscle from $\mathrm{C} 1$ to $\mathrm{C} 3$ vertebra. Remove carefully the both slides $\mathrm{C} 2$ vertebral plate with a corneal scissors (Majestic, UK). Use tooth forceps hook up the dura at C2 and cut it with 11\#surgical blade.

The right $\mathrm{C} 2$ lateral section were performed with microscissors (group A) or microblade (group B) just caudal to the $\mathrm{C} 2$ dorsal roots which means cut close to superior margin of $\mathrm{C} 2$ vertebral body. There was need to note in this step. In group A, one blade of microscissors initially inserted into cervical cord along anteroposterior at lateral 1/4 C2 cord transverse diameter, and the other blade inserted into the space outside edge. Then cut. If ipsilateral EMG still existed, move insert point to medial line a little and repeat the above actions until ipsilateral EMG disappeared.

In group $B$, the blade of microscalpel also inserted into cervical cord along anteroposterior at lateral $1 / 4$ C2 cord transverse diameter and made an incision to edge. If ipsilateral EMG still existed, move insert point to medial line a little and repeat the above actions until ipsilateral EMG disappeared.

\subsection{Histological evaluation the extent of $\mathrm{C2}$ injury}

Two weeks after HS, the survival rats were sacrificed. Rats were transcardially perfused with $200 \mathrm{ml}$ cold $0.9 \%$ saline and $200 \mathrm{ml} 4 \%$ paraformaldehyde. The sample of C1-C3 segment were harvested and followed those procedures: 1) post-fixation in paraformaldehyde overnight, 2) cryoprotection in 50\% ethanol $120 \mathrm{~min}, 70 \%$ ethanol $180 \mathrm{~min}, 85 \%$ ethanol $180 \mathrm{~min}, 95 \%$ ethanol $120 \mathrm{~min}, 90 \mathrm{~min}, 100 \%$ ethanol $30 \mathrm{~min}, 60 \mathrm{~min}, 60 \mathrm{~min} .3)$ xylene $20 \mathrm{~min}, 30 \mathrm{~min}, 4)$ soak in liquid histowax $60^{\circ} \mathrm{C} 120 \mathrm{~min}, 90 \mathrm{~min}, 30 \mathrm{~min}$. The slices were cut with Leica RM2245 (German) in the coronal plane at $6 \mu \mathrm{m}$ thickness and dyed with HE. Slides were then observed with biomicroscope (OLYMMPUS,Japan). Each picture was scan by () and analyzed with Image $\mathrm{J}$ software $(\mathrm{NIH})$.

\subsection{Data Analysis}

Data were expressed as means \pm SD (standard deviation). The Statistical Product and Service Solutions (SPSS) 25.0 software (SPSS, USA) was applied for statistical analyses. The cut frequency and the recovery of peak RMS EMG between the two groups were compared by $t$ test. $p<0.05$ was indicated as statistically significant.

\section{Results}

\subsection{Cut frequency}


In both groups, EMG disappeared immediately after C2HS (Figure1). It means both microscissors and microscalpel can be used to cut spinal cord. However, there was a difference in cut frequency between two groups (Figure2). Group A had litter cut frequency than group B. Less cut frequency meat smoother incisal edge and narrower lesion, which benefits axon regeneration through scar.

\subsection{The extent of $\mathrm{C} 2$ lesion}

We chose one representative HE stain picture from each group. We can see $\mathrm{C} 2$ lesion in group $\mathrm{B}$ was larger than that in group A (figure 3). Obviously, it was nearly impossible that cut at one initial site on C2 cord too many times.

\subsection{Peak RMS EMG}

On the 14th days post injury, a variety of EMG recovery happened (figure 4). Group A had larger percent of peak RMS EMG post injury to that before injury than group B (figure 5). That means the more motor unit recruited in group $A$.

\subsection{Survival rate}

We calculated the 14-day post injury survival rate in group A and group B. The survival rate in group $A$ was $80 \%$ and in group B was $60 \%$. All death happened in 1-day post injury. There was no pneumothorax during electrode implant or hemorrhage during laminectomy in both groups. We assumed the respiratory inhibition caused by $\mathrm{C} 2 \mathrm{HS}$ can attribute for all the death.

\section{Discussion}

The present study, we made rat lateral $\mathrm{C} 2 \mathrm{HS}$ model separately with microscissor and microscalpel. the first time cut frequency, 14 days survival rate, the extent of $\mathrm{C} 2$ injury, and percent of peak RMS EMG post injury to that before injury on performed with two different surgical procedures during anesthesia. As a result, we found that microscissor, comparing microscalpel, caused milder C2 injury extent, higher survival rate on the 14th day post injury, and higher percent of peak RMS EMG post injury to that before injury. However, microscissor need larger cut frequency during hemisection.

\section{Structure characteristics of Spinal canal}

We had two reasons to performed lateral C2 hemisection just above superior margin of C2 vertebral body. First, we dissected two rats and found $\mathrm{C} 2$ nerve root arise just above superior margin of $\mathrm{C} 2$ vertebral body and performing lateral C2 hemisection close to superior margin of C2 vertebral body can avoid C3 hemisection erroneously. Second, it is difficult for the microscissor to cut the cervical cord edge at vertebral level because of the curved sidewall of spinal canal.

\section{Structure characteristics of hemisection tool}

As for microscissor, the length of blade of microscissor seem to go into dilemma. Both long blade and short blade are disadvantage to cut the cervical cord edge. Too long blade was disadvantage for fine 
manipulation and too short blade cannot cut C2 spinal cord once. In this study, we use microscissors with $14 \mathrm{~mm}$ long blade and we found its blade length were appropriate.

Tough dura mater was easy to out of shape before pierced and this deformation caused C2 spinal cord crush injury which was devastating. The lateral dura mater in this study cannot be cut due to pedicle of vertebral arch. As for microscalpel, cutting cervical cord from middle to lateral avoid piercing lateral dura mater. As for microscissor, one blade must pierce lateral dura mater before cut spinal cord. Therefore, microscalpel seem better.

\section{The extent of C2 injury}

Fuller DD reported that the sparing of ventromedial (VM) tissue caused different ventilation and phrenic nerve activity ipsilateral to $\mathrm{C} 2$ lesion from complete $\mathrm{C} 2 \mathrm{HS}$ and confirmed that descending respiratory projections from the brainstem were present in VM tissue by anterograde neuroanatomical tracing 47 . Lipski further proposed that rVRG projects ipsilateral axons in the lateral funiculus and contralateral axons in the ventral funiculus ${ }^{48}$. This idea was indirectly confirmed by Vinit and he reported that the transection of median (include VM) did not abolish the ipsilateral hemidiaphragm activity but the lateral one $\mathrm{did}^{6}$. Similar to Vinit, Kenneth $\mathrm{H}$. Minor reported that lateral $\mathrm{C} 2$ area transection with the ventral funiculus sparing leads to a functional silencing of the ipsilateral hemidiaphragm. However, if lateral and lateral ventral funiculus transection were made initially, the recovery was failure ${ }^{28}$. Therefore, we assumed that the lateral area of the ventral funiculus is indispensable for SCPP response and it is sufficient to induces complete ipsilateral hemidiaphragm paralysis by lateral $\mathrm{C} 2$ area transection. Similiar to other studies ${ }^{49}$, we performed C2 lateral HS and ipsilateral hemidiaphragm activity disappeared immediately. It's important to note that it was difficult to cut C2 spinal cord lateral edge with microcissors due to the shield effect of adduction structure of pedicle of vertebral arch. Therefore, one blade of microcissors have to insert spinal cord closed to post middle line so as to the other blade can cut C2 spinal cord lateral edge and this action caused larger but unnecessary lesion area.

\section{EMG during anesthesia and eupnea}

The full extent of spontaneous ipsilateral hemidiaphragm recovery is significantly attenuated by anesthesia, such as ketamine/xylazine, isoflurane, and urethane. Some people reported that there were litter peak RMS EMG in anesthesia rats compared with the awaken rats ${ }^{50} 51$. In this study, rats were anesthetized with $10 \%$ chloral hydrate $(0.3 \mathrm{ml} / 100 \mathrm{~g})$. Therefore, it should be worthy of noting that anesthesia or awaken condition when use this rat model to evaluate EMG.

Some studies have showed robust correlation between transdiaphragmatic pressure (Pdi) and peak RMS $\mathrm{EMG}^{52,53}$. Therefore, there was significance in peak RMS EMG consistency among studies which used different methods. Our result showed that there was no significant difference in peak RMS EMG during anesthesia and eupnea condition between scissors group and knife group at any time point post HS. Therefore, if there was significant difference in percent of peak RMS EMG post HS normalized to that 
before HS among studies which used different methods, the significant difference cannot be attribute to microscissors and microscalpel.

\section{Electrode implantation site}

In some study, they detected the sternal, costal and crural regions of the hemidiaphragm in order to avoid this result what some activity may have been missed due to only one area of the hemidiaphragm detected ${ }^{54}$. That result, however, rare happened. For example, some animals showed an absence of EMG activity in the crural hemidiaphragm also had no EMG activity in the other two regions of the hemidiaphragm in a study of 44 animals ${ }^{55}$. Addition, sternal hemidiaphragm was too small and attribute limitedly to hemidiaphragm movement. Therefore, it was acceptable to electrode implant at costal region alone like this study. More implantation sites mean larger probability of pneumothorax which could be avoid.

\section{The Schedule of HS}

In this study, we performed C2HS on the 3rd days after electrode implantation in order to avoid diaphragm disfunction induced possibly by laparotomy. Following upper abdominal surgery, diaphragm disfunction ${ }^{56-59}$ such as abnormal respiratory frequency, tidal volume $(\mathrm{Vt})$ and transdiaphragmatic pressure (Pdi) appeared because of diaphragmatic reflex inhibition instead of structural impairment ${ }^{60}$ and persisted for 1-2 day ${ }^{61}$ after upper abdominal surgery until pain relief ${ }^{57}$. In P. A. Easton study ${ }^{62}$, for example, rats without any peridiaphragmatic contact also had diaphragm reflex inhibition only due to abdomen incision. Therefore, it is better to performed $\mathrm{C} 2 \mathrm{HS}$ on the 3rd days after electrode implantation.

\section{Technical difficulties of electrode implantation}

The details of electrode implantation were unclear in many literatures. In this study, electrode puncture needle was custom-made with $25 \mathrm{G}$ syringe needle. The puncture needle through full layer diaphragm was a challenge due to the high incidence of pneumothorax when the diaphragm was perforated. Therefore, we try half layer diaphragm with electrode puncture needle. And the electrode implantation site located in the diaphragm crural region and on the border line between diaphragm and chest wall. In the early stage of this study, the formation of scar tissue about 21 day after surgery at the site of muscle insertion decreased the signal output and this phenomenon is similar to the study of Philippa M. Warren ${ }^{55}$. His solution was that the electrode implant was repeated in a rat every recording. However, multiple abdominal surgeries must inevitably affect diaphragmatic reflex. Not to mention, EMG comparation under different electrode implantation site condition had no significance. Fortunately, scar tissue within 14 days was not enough to affect EMG and that was the reason why EMG measurement ended up on the 14th day after C2HS.

\section{Gender-related differences in survival rate}


As M Farooque reported, female mice on the 14th day after thoracic 10 compression $\mathrm{SCl}$ have less severity initial injury and higher Basso, Beattie and Bresnahan scores than male mice. The mechanism(s) of neuroprotection effects of estrogen on pathophysiological processes such as blood flow, leukocyte migration inhibition, antioxidant properties, and inhibition of apoptosis might attribute this differences ${ }^{63}$. Similarly, in our pre-study, all the three months old male rats dead eight hours after and all the three months old female rats survived. We had speculated this difference might attribute to weight because female rats only weight $3 / 5$ male rats at same yearth level. Therefore, in our pre-study, we repeat $\mathrm{C} 2 \mathrm{HS}$ using $300 \mathrm{~g}$ male rats and $300 \mathrm{~g}$ female rats. However, this result did not change. Therefore, weight cannot contribute to that difference and estrogen might, although not yet elucidated, contribute to that difference like M Farooque's study. Therefore, in this study, we only use female rats so as to avoid death.

\section{Conclusion}

The rat model of lateral $\mathrm{C} 2$ hemisection was an emergent tool to study CPP. However, there were mainly two experiment methods in several studies-microscissors or microscalpel. We compared those two methods and found microscissors csused milder $\mathrm{C} 2$ lesion than microscalpel, higher 14 days survival rate, and higher percent of peak RMS EMG 14 days post C2SH to that before injury. However, microscissors had larger cut frequency during hemisection. Weigh the advantages and disadvantages, microscissors seems had superiority over microscissors.

\section{Declarations}

\section{Funding}

This research did not receive any specific grant from funding agencies in the public, commercial, or notfor-profit sectors.

\section{Conflict of interest}

The authors declare that they have no conflict of interest.

\section{Contribution}

Kai Wang and Liang Zhang contributed to the study conception and design. LinLin Shen performed experiment and wrote the manuscript. Chen Song made statistics and figures.

\section{References}

1. Fuller DD, Doperalski NJ, Dougherty BJ, Sandhu MS, Bolser DC, Reier PJ. Modest spontaneous recovery of ventilation following chronic high cervical hemisection in rats. Exp Neurol. May 2008;211(1):97-106.

2. Bezdudnaya T, Marchenko V, Zholudeva LV, Spruance VM, Lane MA. Supraspinal respiratory plasticity following acute cervical spinal cord injury. Exp Neurol. Jul 2017;293:181-189. 
3. Dougherty BJ, Lee KZ, Lane MA, Reier PJ, Fuller DD. Contribution of the spontaneous crossed-phrenic phenomenon to inspiratory tidal volume in spontaneously breathing rats. J Appl Physiol (1985). Jan 2012;112(1):96-105.

4. Mantilla CB, Gransee HM, Zhan WZ, Sieck GC. Impact of glutamatergic and serotonergic neurotransmission on diaphragm muscle activity after cervical spinal hemisection. J Neurophysiol. Sep 1 2017;118(3):1732-1738.

5. Goshgarian HG. The crossed phrenic phenomenon and recovery of function following spinal cord injury. Respir Physiol Neurobiol. Nov 30 2009;169(2):85-93.

6. Vinit S, Gauthier P, Stamegna JC, Kastner A. High cervical lateral spinal cord injury results in long-term ipsilateral hemidiaphragm paralysis. J Neurotrauma. Jul 2006;23(7):1137-1146.

7. Goshgarian HG. The crossed phrenic phenomenon: a model for plasticity in the respiratory pathways following spinal cord injury. J Appl Physiol (1985). Feb 2003;94(2):795-810.

8. Goshgarian HG. Developmental plasticity in the respiratory pathway of the adult rat. Exp Neurol. Dec 1979;66(3):547-555.

9. Lane MA, Fuller DD, White TE, Reier PJ. Respiratory neuroplasticity and cervical spinal cord injury: translational perspectives. Trends Neurosci. Oct 2008;31(10):538-547.

10. Mantilla CB, Greising SM, Zhan WZ, Seven YB, Sieck GC. Prolonged C2 spinal hemisection-induced inactivity reduces diaphragm muscle specific force with modest, selective atrophy of type IIx and/or Illb fibers. J Appl Physiol (1985). Feb 2013;114(3):380-386.

11. Rosenblueth A, Ortiz T. THE CROSSED RESPIRATORY IMPULSES TO THE PHRENIC. American Journal of Physiology-Legacy Content. 1936;117(3):495-513.

12. Ghali MGZ. The crossed phrenic phenomenon. Neural regeneration research. 2017;12(6):845-864.

13. O'Hara TE, Jr., Goshgarian HG. Quantitative assessment of phrenic nerve functional recovery mediated by the crossed phrenic reflex at various time intervals after spinal cord injury. Exp Neurol. Feb 1991;111(2):244-250.

14. Fuller DD, Johnson SM, Olson EB, Jr., Mitchell GS. Synaptic pathways to phrenic motoneurons are enhanced by chronic intermittent hypoxia after cervical spinal cord injury. J Neurosci. Apr 1 2003;23(7):2993-3000.

15. Fuller DD, Golder FJ, Olson EB, Jr., Mitchell GS. Recovery of phrenic activity and ventilation after cervical spinal hemisection in rats. J Appl Physiol (1985). Mar 2006;100(3):800-806. 
16. Vinit S, Stamegna JC, Boulenguez P, Gauthier P, Kastner A. Restorative respiratory pathways after partial cervical spinal cord injury: role of ipsilateral phrenic afferents. Eur J Neurosci. Jun 2007;25(12):3551-3560.

17. Golder FJ, Mitchell GS. Spinal synaptic enhancement with acute intermittent hypoxia improves respiratory function after chronic cervical spinal cord injury. J Neurosci. Mar 16 2005;25(11):2925-2932.

18. Golder FJ, Reier PJ, Davenport PW, Bolser DC. Cervical spinal cord injury alters the pattern of breathing in anesthetized rats. J Appl Physiol (1985). Dec 2001;91(6):2451-2458.

19. Nantwi KD, El-Bohy AA, Schrimsher GW, Reier PJ, Goshgarian HG. Spontaneous Functional Recovery in a Paralyzed Hemidiaphragm Following Upper Cervical Spinal Cord Injury in Adult Rats. Neurorehabilitation and Neural Repair. 1999/12/01 1999;13(4):225-234.

20. Lane MA, White TE, Coutts MA, et al. Cervical prephrenic interneurons in the normal and lesioned spinal cord of the adult rat. The Journal of comparative neurology. 2008;511(5):692-709.

21. Fuller DD, Sandhu MS, Doperalski NJ, et al. Graded unilateral cervical spinal cord injury and respiratory motor recovery. Respir Physiol Neurobiol. Feb 28 2009;165(2-3):245-253.

22. Lane MA, Lee KZ, Fuller DD, Reier PJ. Spinal circuitry and respiratory recovery following spinal cord injury. Respir Physiol Neurobiol. Nov 30 2009;169(2):123-132.

23. Sandhu MS, Dougherty BJ, Lane MA, et al. Respiratory recovery following high cervical hemisection. Respir Physiol Neurobiol. Nov 30 2009;169(2):94-101.

24. Murray M, Goldberger ME. Restitution of function and collateral sprouting in the cat spinal cord: The partially hemisected animal. Journal of Comparative Neurology. 1974;158(1):19-36.

25. Mc CG, Austin GM, Liu CN, Liu CY. Sprouting as a cause of spasticity. J Neurophysiol. May 1958;21(3):205-216.

26. Goldberger ME, Murray M. Restitution of function and collateral sprouting in the cat spinal cord: the deafferented animal. J Comp Neurol. Nov 1 1974;158(1):37-53.

27. Bernstein ME, Bernstein JJ. Regeneration of axons and synaptic complex formation rostral to the site of hemisection in the spinal cord of the monkey. Int J Neurosci. Jan 1973;5(1):15-26.

28. Minor KH, Akison LK, Goshgarian HG, Seeds NW. Spinal cord injury-induced plasticity in the mousethe crossed phrenic phenomenon. Exp Neurol. Aug 2006;200(2):486-495.

29. Liou WW, Goshgarian HG. Quantitative assessment of the effect of chronic phrenicotomy on the induction of the crossed phrenic phenomenon. Exp Neurol. May 1994;127(1):145-153. 
30. Basura GJ, Nantwi KD, Goshgarian HG. Theophylline-induced respiratory recovery following cervical spinal cord hemisection is augmented by serotonin 2 receptor stimulation. Brain Res. Nov 22 2002;956(1):1-13.

31. Huang Y, Goshgarian HG. The potential role of phrenic nucleus glutamate receptor subunits in mediating spontaneous crossed phrenic activity in neonatal rat. International journal of developmental neuroscience : the official journal of the International Society for Developmental Neuroscience. 2009;27(5):477-483.

32. Fuller DD, Doperalski NJ, Dougherty BJ, Sandhu MS, Bolser DC, Reier PJ. Modest spontaneous recovery of ventilation following chronic high cervical hemisection in rats. Experimental neurology. 2008;211(1):97-106.

33. Bezdudnaya T, Marchenko V, Zholudeva LV, Spruance VM, Lane MA. Supraspinal respiratory plasticity following acute cervical spinal cord injury. Experimental neurology. 2017;293:181-189.

34. Dougherty BJ, Lee K-Z, Lane MA, Reier PJ, Fuller DD. Contribution of the spontaneous crossed-phrenic phenomenon to inspiratory tidal volume in spontaneously breathing rats. Journal of applied physiology (Bethesda, Md : 1985). 2012;112(1):96-105.

35. Alilain WJ, Horn KP, Hu H, Dick TE, Silver J. Functional regeneration of respiratory pathways after spinal cord injury. Nature. 2011;475(7355):196-200.

36. Golder FJ, Reier PJ, Bolser DC. Altered respiratory motor drive after spinal cord injury: supraspinal and bilateral effects of a unilateral lesion. J Neurosci. Nov 1 2001;21(21):8680-8689.

37. Lee K-Z, Huang Y-J, Tsai I-L. Respiratory motor outputs following unilateral midcervical spinal cord injury in the adult rat. Journal of Applied Physiology. 2014;116(4):395-405.

38. Lee KZ, Hsu SH. Compensatory Function of the Diaphragm after High Cervical Hemisection in the Rat. J Neurotrauma. Sep 15 2017;34(18):2634-2644.

39. Mantilla CB, Gransee HM, Zhan W-Z, Sieck GC. Impact of glutamatergic and serotonergic neurotransmission on diaphragm muscle activity after cervical spinal hemisection. Journal of neurophysiology. 2017;118(3):1732-1738.

40. Siu R, Abbas JJ, Hillen BK, et al. Restoring Ventilatory Control Using an Adaptive Bioelectronic System. Journal of neurotrauma. 2019;36(24):3363-3377.

41. Gransee HM, Gonzalez Porras MA, Zhan W-Z, Sieck GC, Mantilla CB. Motoneuron glutamatergic receptor expression following recovery from cervical spinal hemisection. The Journal of comparative neurology. 2017;525(5):1192-1205. 
42. Alvarez-Argote S, Gransee HM, Mora JC, et al. The Impact of Midcervical Contusion Injury on Diaphragm Muscle Function. J Neurotrauma. Mar 1 2016;33(5):500-509.

43. Gransee HM, Zhan WZ, Sieck GC, Mantilla CB. Localized delivery of brain-derived neurotrophic factorexpressing mesenchymal stem cells enhances functional recovery following cervical spinal cord injury. $J$ Neurotrauma. Feb 1 2015;32(3):185-193.

44. Mantilla CB, Seven YB, Hurtado-Palomino JN, Zhan WZ, Sieck GC. Chronic assessment of diaphragm muscle EMG activity across motor behaviors. Respir Physiol Neurobiol. Jul 31 2011;177(2):176-182.

45. Martínez-Gálvez G, Zambrano JM, Diaz Soto JC, et al. TrkB gene therapy by adeno-associated virus enhances recovery after cervical spinal cord injury. Exp Neurol. Feb 2016;276:31-40.

46. Keomani E, Deramaudt TB, Petitjean M, Bonay M, Lofaso F, Vinit S. A murine model of cervical spinal cord injury to study post-lesional respiratory neuroplasticity. Journal of visualized experiments : JoVE. 2014(87):51235.

47. Fuller DD, Sandhu MS, Doperalski NJ, et al. Graded unilateral cervical spinal cord injury and respiratory motor recovery. Respiratory physiology \& neurobiology. 2009;165(2-3):245-253.

48. Lipski J, Zhang X, Kruszewska B, Kanjhan R. Morphological study of long axonal projections of ventral medullary inspiratory neurons in the rat. Brain Res. Mar 21 1994;640(1-2):171-184.

49. Vinit S, Keomani E, Deramaudt TB, Bonay M, Petitjean M. Reorganization of Respiratory Descending Pathways following Cervical Spinal Partial Section Investigated by Transcranial Magnetic Stimulation in the Rat. PloS one. 2016;11(2):e0148180-e0148180.

50. Jimenez-Ruiz F, Khurram OU, Zhan W-Z, Gransee HM, Sieck GC, Mantilla CB. Diaphragm muscle activity across respiratory motor behaviors in awake and lightly anesthetized rats. Journal of applied physiology (Bethesda, Md : 1985). 2018;124(4):915-922.

51. Bezdudnaya T, Hormigo KM, Marchenko V, Lane MA. Spontaneous respiratory plasticity following unilateral high cervical spinal cord injury in behaving rats. Experimental neurology. 2018;305:56-65.

52. Gill LC, Mantilla CB, Sieck GC. Impact of unilateral denervation on transdiaphragmatic pressure. Respiratory physiology \& neurobiology. 2015;210:14-21.

53. Mantilla CB, Seven YB, Zhan W-Z, Sieck GC. Diaphragm motor unit recruitment in rats. Respiratory physiology \& neurobiology. 2010;173(1):101-106.

54. Kramer C, Jordan D, Kretschmer A, et al. Electromyographic permutation entropy quantifies diaphragmatic denervation and reinnervation. PloS one. 2014;9(12):e115754-e115754. 
55. Warren PM, Steiger SC, Dick TE, MacFarlane PM, Alilain WJ, Silver J. Rapid and robust restoration of breathing long after spinal cord injury. Nature communications. 2018;9(1):4843-4843.

56. Tahir AH, George RB, Weill H, Adriani J. Effects of abdominal surgery upon diaphragmatic function and regional ventilation. Int Surg. May 1973;58(5):337-340.

57. Simonneau G, Vivien A, Sartene R, et al. Diaphragm dysfunction induced by upper abdominal surgery. Role of postoperative pain. Am Rev Respir Dis. Nov 1983;128(5):899-903.

58. Easton PA, Fitting JW, Arnoux R, Guerraty A, Grassino AE. Recovery of diaphragm function after laparotomy and chronic sonomicrometer implantation. J Appl Physiol (1985). Feb 1989;66(2):613-621.

59. Dureuil B, Viirès N, Cantineau JP, Aubier M, Desmonts JM. Diaphragmatic contractility after upper abdominal surgery. J Appl Physiol (1985). Nov 1986;61(5):1775-1780.

60. Pasteur W. ACTIVE LOBAR COLLAPSE OF THE LUNG AFTER ABDOMINAL OPERATIONS.: A CONTRIBUTION TO THE STUDY OF POST-OPERATIVE LUNG COMPLICATIONS. The Lancet. 1910/10/08/ 1910;176(4545):1080-1083.

61. Ford GT, Whitelaw WA, Rosenal TW, Cruse PJ, Guenter CA. Diaphragm function after upper abdominal surgery in humans. Am Rev Respir Dis. Apr 1983;127(4):431-436.

62. Easton PA, Fitting JW, Arnoux R, Guerraty A, Grassino AE. Recovery of diaphragm function after laparotomy and chronic sonomicrometer implantation. Journal of Applied Physiology. 1989;66(2):613621.

63. Farooque M, Suo Z, Arnold PM, et al. Gender-related differences in recovery of locomotor function after spinal cord injury in mice. Spinal Cord. Mar 2006;44(3):182-187.

\section{Figures}




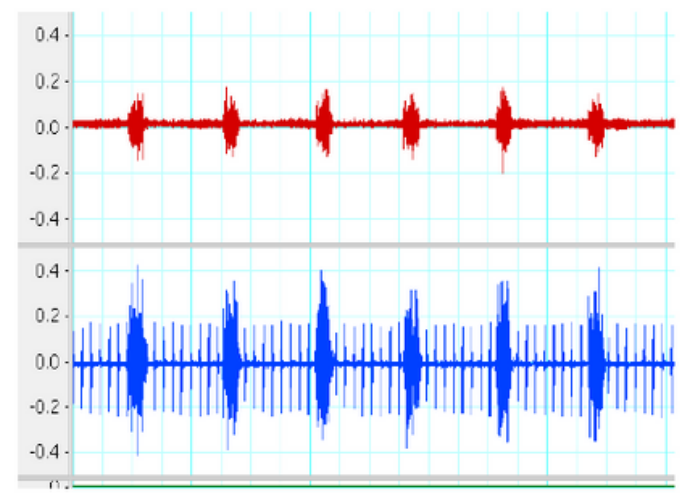

A1

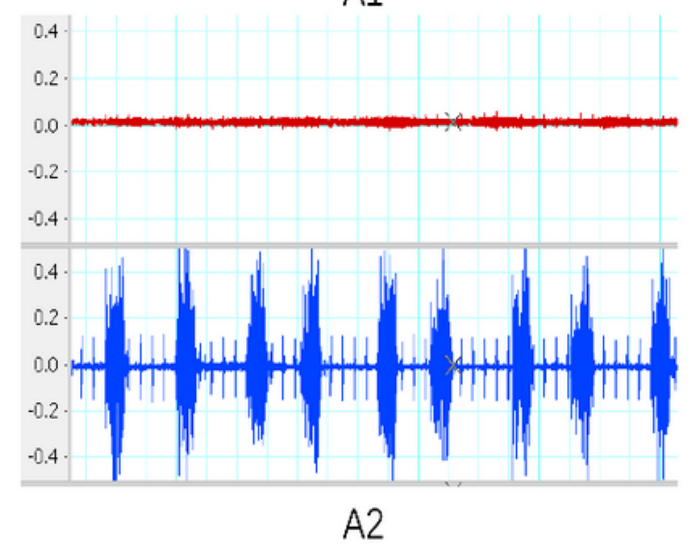

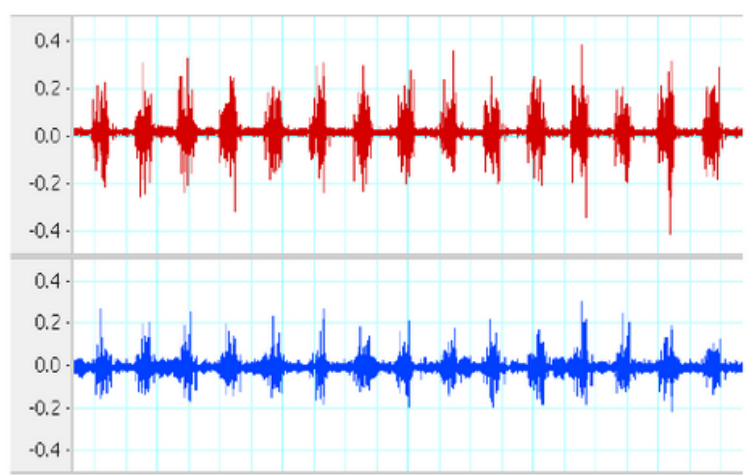

B1

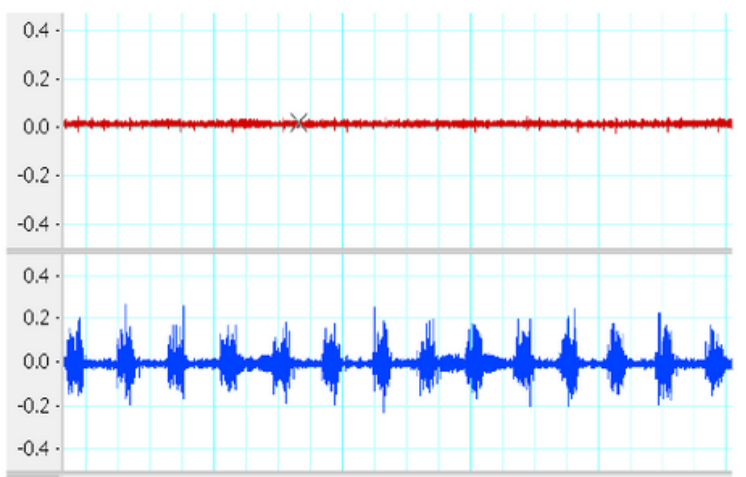

B2

Figure 1

EMG recorded a few miniutes before and after $\mathrm{C} 2 \mathrm{HS}$. The EMG of a rat from group $\mathrm{A}$ before (A1) and after (A2) C2HS. The EMG of a rat from group B before (B1) and after (B2) C2HS. 


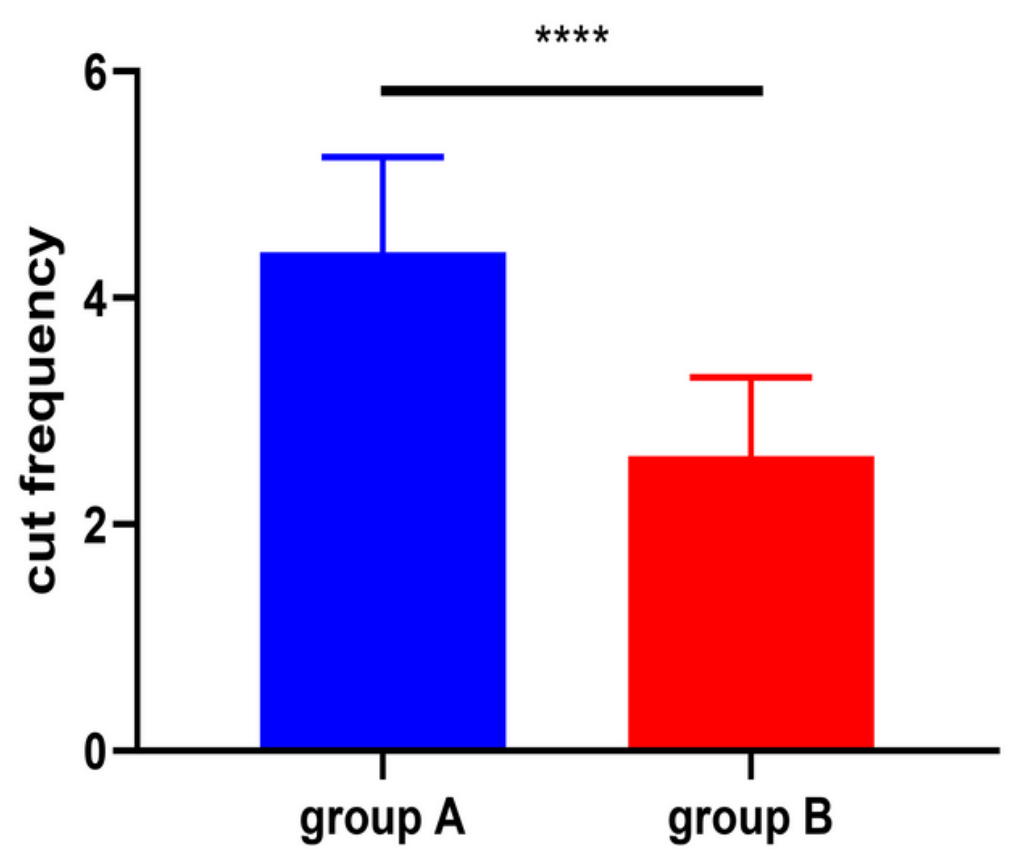

Figure 2

The cut frequency during hemisection in group A was larger than that in group B. ${ }^{\star \star \star \star} p<0.0001$ 


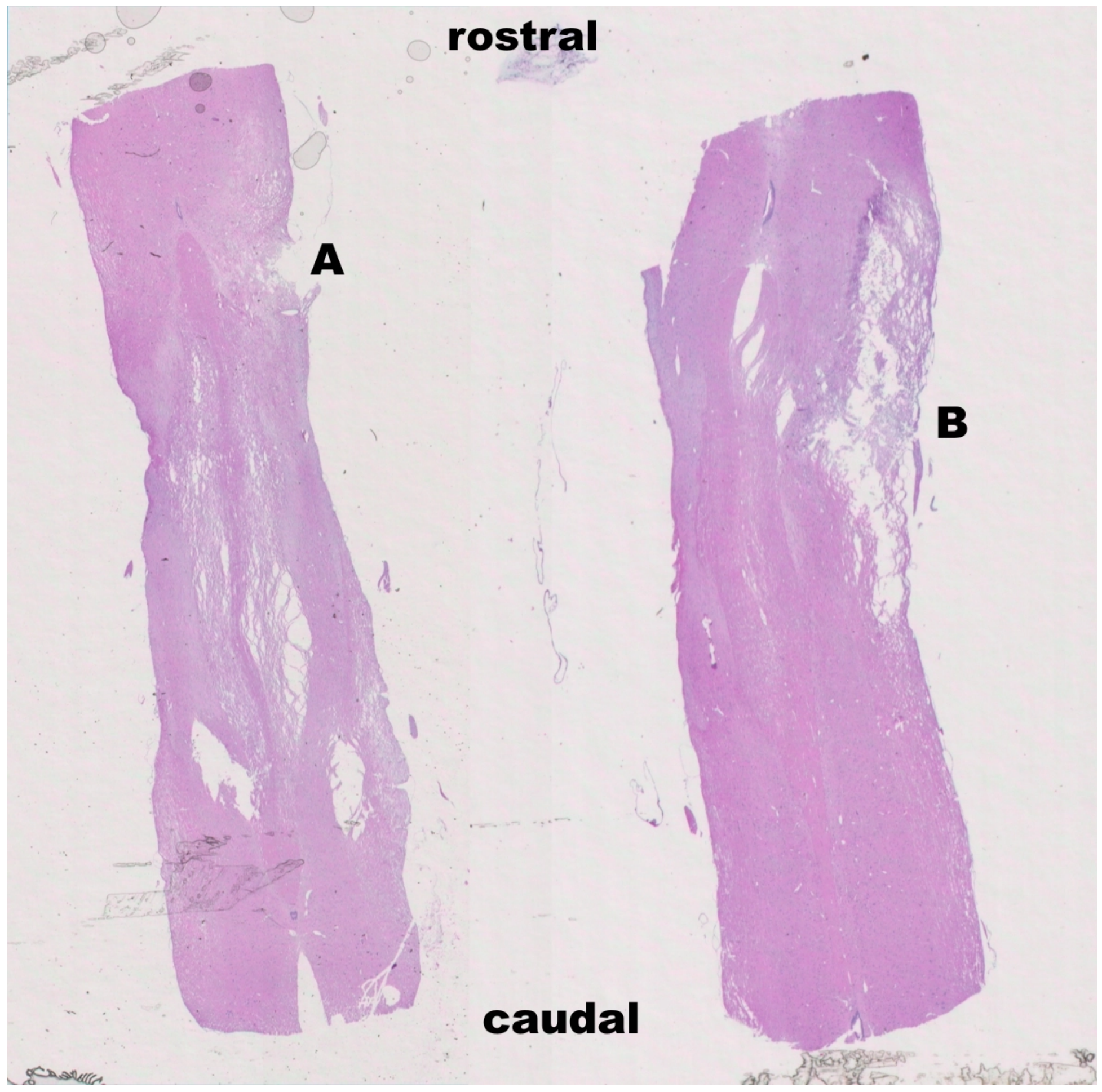

\section{Figure 3}

C1 C3 spinal cord coronal plane. Two representative HE stain pictures from Group A (left) and group B (right) separately. " $\mathrm{A}$ " and " $\mathrm{B}$ " indicate the cut location. The port closed to medial line was spared in both groups. And the lesion in group $B$ in was larger than that in group $B$ in rostral-caudal level and lateral level. 

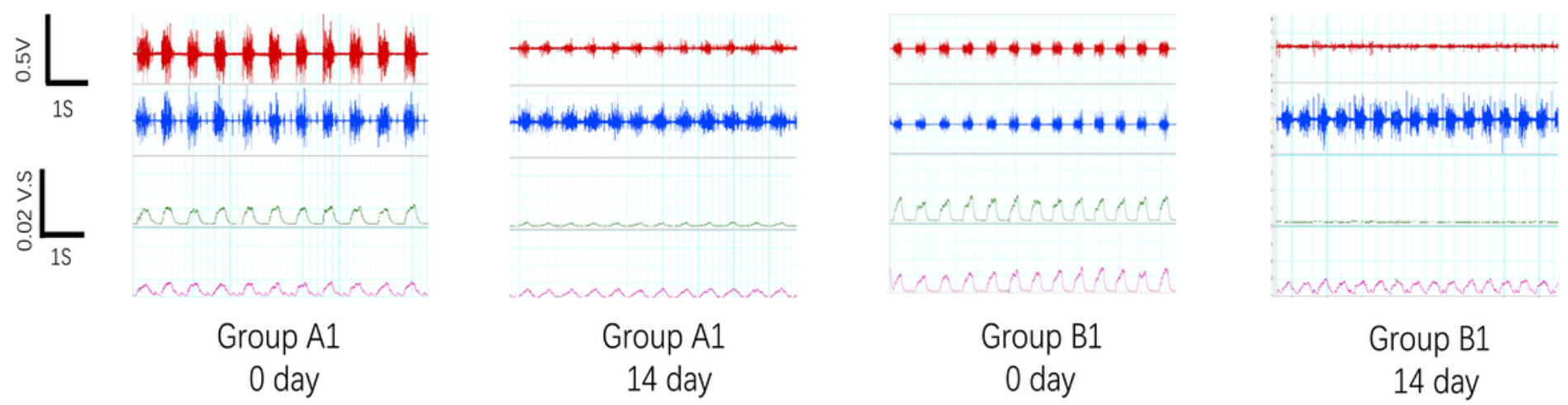
Group B1
0 day

Group B1

14 day
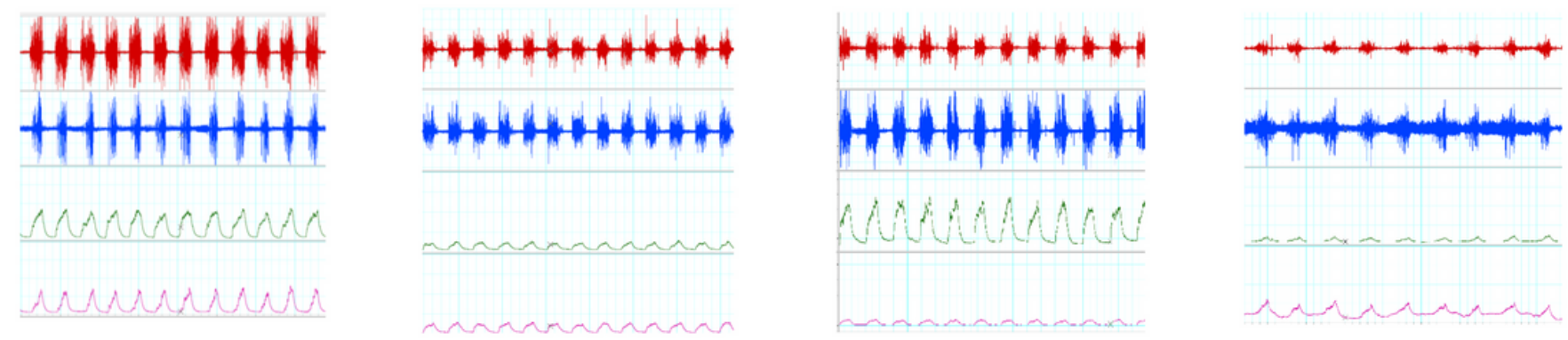

$\begin{array}{cc}\text { Group A2 } & \text { Group A2 } \\ 0 \text { day } & 14 \text { day }\end{array}$
Group B2
0 day

Group B2

14 day

\section{Figure 4}

The representative EMG that recorded on the 3 days before $\mathrm{C} 2 \mathrm{HS}$ as well as the 14 th day post $\mathrm{C} 2 \mathrm{HS}$ of two rats in each group. A1 and A2 were two rats from group A. B1 and B2 were two rats from group B. In each EMG, upper 2 panel were raw EMG, red: right hemidiaphragm. blue:left hemidiaphragm. Lower 2 panel were RMS EMG. green: right hemidiaphragm. purple: left hemidiaphragm. 


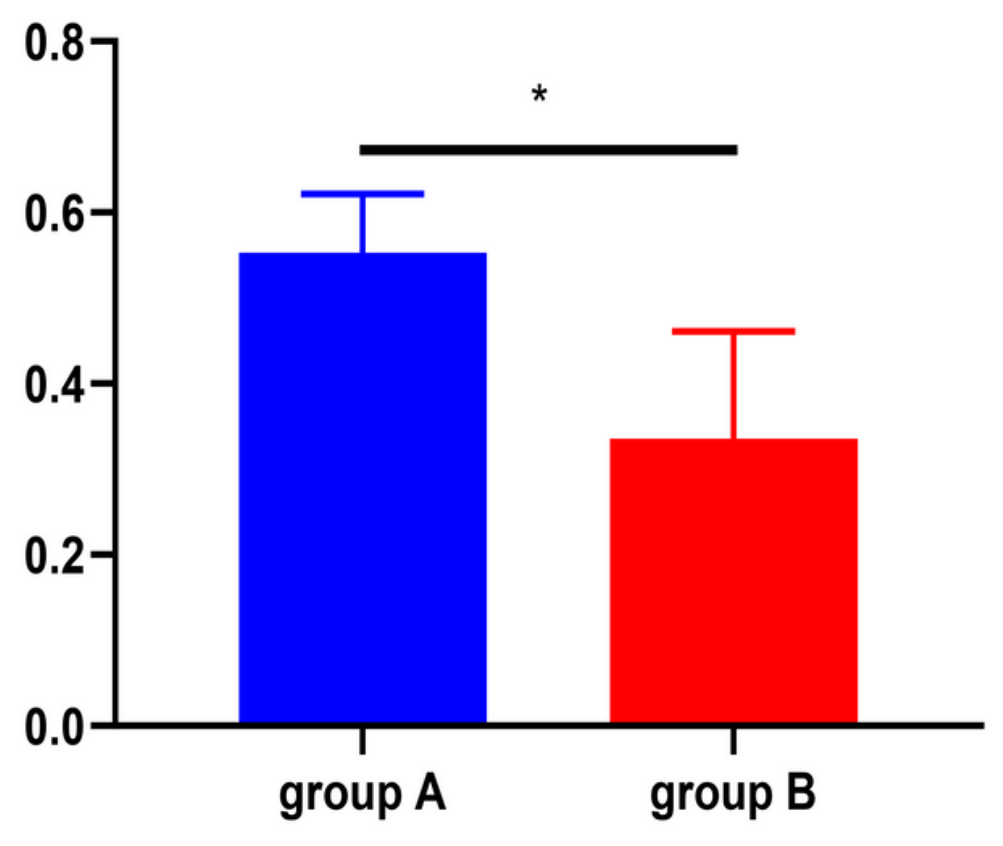

\section{Figure 5}

The group A had higher percent of peak RMS EMG any time point post injury to that before injury. And that means larger motor unit recruitment was happened in group $A . * p<0.05$ 